\title{
Economic Cost of Diabetes in Ampara District in Sri Lanka
}

\author{
S. M. Ahamed Lebbe ${ }^{1} \&$ K. Fathima Rinosha ${ }^{1}$ \\ ${ }^{1}$ Department of Economics and Statistics, South Eastern University of Sri Lanka, Sri Lanka \\ Correspondence: S. M. Ahamed Lebbe, Department of Economics and Statistics, South Eastern University of Sri \\ Lanka, Sri Lanka. E-mail: smahamed@seu.ac.lk; frinosha92@gmail.com
}

Received: October 1, 2018

Accepted: October 19, $2018 \quad$ Online Published: November 30, 2018

doi:10.5539/jpl.v11n4p146

URL: https://doi.org/10.5539/jpl.v11n4p146

\begin{abstract}
Economic cost of diabetes comprises of two components, viz. the direct cost and indirect cost. Doctor consultation fees, transportation cost, cost of blood and urine tests, and cost of medication constitute the direct cost. Short term morbidity and permanent disability due to diabetes result in inability to work, which accounts for the indirect cost. The objective of the study was to measure the economic cost of diabetic patients in Sainthamaruthu Divisional Secretariat Area of Ampara district in Sri Lanka. The research area of this study was Sainthamaruthu Township in Ampara district, where the burden of diabetes is higher than in other places. This study used primary and secondary data, both qualitative and quantitative. Primary data was collected through a questionnaire. Sample was selected through the stratified sampling method from 243 patients. 100 questionnaires were distributed through the random sampling method. For the data analysis this study used cross-sectional descriptive method. The direct cost and indirect cost of diabetes was estimated by cost of illness method. Analysis was performed through SPSS and Excel. This survey found that the monthly average direct cost per patient in Sainthamaruthu Divisional Secretariat Area was US \$19. A breakdown gives monthly average doctor consultation fees of US $\$ 5.15$, monthly average transportation cost of US $\$ 1.12$, monthly average cost for urine test US $\$ 0.47$, monthly average cost for blood test US $\$ 1.32$, and monthly average medication cost of US $\$ 10.93$. To these must be added monthly average indirect cost of US $\$ 68.94$. This is made up of US $\$ 49.20$ lost per patient per month for permanent disability and US $\$ 19.74$ lost per patient per month for short term morbidity. Therefore, the monthly average economic cost amounted to US $\$ 87.93$ per patient. At the same time, a higher level of economic cost is borne by the male and lower cost borne by the income group that earned between US $\$ 175$ and US \$350. 54 percent of patients depend on their families to meet their diabetes related expenditure. So the major part of the cost of diabetes care is imposed on the families of diabetic patients in the study area. And it just proves to be a big economic burden on them.
\end{abstract}

Keywords: cost of illness, diabetes mellitus, disability, morbidity

\section{Introduction}

The term Diabetes refers to a group of metabolic diseases in which the blood sugar levels remain high over a prolonged period. Symptoms of high blood sugar include frequent urination, increased thirst, and increased hunger. Incidence of Diabetes is currently increasing all over the world and the cost of managing the disease has to be borne by the patients for their entire life (Breckenridge, Page \& Richard, 1998).

That is the reason why diabetes brings economic hardships to the patients and their families while also being a burden on the national economy. So, based on this, the economic cost of diabetes is assessed in terms of its direct cost and indirect cost. The direct cost of diabetes includes medication cost, doctor consultation fees, travelling cost, cost for urine test and cost for blood test. At the same time, production losses due to sick leave, early retirement and premature death due to diabetes are categorized as the indirect cost of diabetes (Cobden, 2011).

Diabetes is a disease that is rapidly increasing in all countries, and imposing a substantial burden on the world economy. Globally, an estimated 422 million adults were living with diabetes in 2014, compared to 108 million in 1980. The prevalence of diabetes worldwide has nearly doubled since 1980, rising from 4.7 percent to 8.5 percent among the adult population. Diabetes caused 1.5 million deaths in 2012. Higher-than-optimal blood glucose levels caused an additional 2.2 million deaths by increasing the risks for people with cardiovascular and other diseases. 43 percent of these 3.7 million deaths occurred before the age of 70 years (World Health Organization [WHO], 2014). 
Sri Lanka being a lower middle income country is faced with a shortage of both financial and human resources to handle the growing prevalence of diabetes even though the Sri Lankan healthcare system is among the more efficient of those in developing countries. According to the Diabetes Association of Sri Lanka (DASL), in 2014 more and more young persons were being afflicted by the disease and the overall number of people affected by it was also increasing. The prevalence of diabetes in the country had dramatically increased from around 16 percent in 2009 to 20 percent in 2014. Interestingly, the prevalence of diabetes among people over 20 years in the urban population was 16 percent but among the rural population it was much lower, at eight percent.

For those below the age of 20 years it was 8.2 percent overall. According to DASL, diabetes among the urban population had increased from 12.1 percent in 1996 to 16.4 percent in 2008. Overall prevalence increased from 6.87 percent in 1987 to 30 percent in 2006 (www.diabetessrilanka.org).

Healthcare expenditure on diabetes accounted for 11.6 percent of the total healthcare expenditure in the world in 2010. The percentage varied from 7 percent in the African Region to 14 percent in the Middle East and North African Region, North America and Caribbean Region. However, there was a wide variation by country. Even in Sri Lanka $\$ 106,802$ was spent for diabetes treatment in 2010. It is expected to rise to $\$ 149,933$ in 2030 (WHO, 2011).

Reflecting these statistics, the study area also shows a rapid increase in the prevalence of diabetes. Therefore, the study investigated the economic cost of diabetes in terms of direct cost and indirect cost in Sainthamaruthu.

\subsection{Research Problem}

In the study area there were 243 people afflicted with diabetes in 2016. It had increased compared with the previous year when it was 235 . The economic burden of diabetes on patients and their families in the study area was much higher compared to other diseases according to the records of the Sainthamaruthu Divisional Secretariat. Cases of other diseases that were recorded in 2015 were very low compared to diabetes. This is shown in the chart below.

Table 1. Diseases common among Sainthamaruthu population in 2015

\begin{tabular}{ll}
\hline Disease & No. of people \\
\hline No. of Tuberculosis cases & 9 \\
No. of registered Leprosy cases & 4 \\
No. of Diabetes mellitus cases & 235 \\
No. of dogs vaccinated & - \\
No. of registered Dengue fever cases & 44 \\
\hline
\end{tabular}

(Source: Sainthamaruthu Divisional Secretariat, 2015)

Many of the diabetic patients in the study area spend a significant part of their income for the treatment of diabetes. The Sainthamaruthu population includes more middle income and lower income groups than other places in Ampara District. So they face a critical situation when seeking treatment because the prices of medicines, medical tests, doctors' fees and travelling costs are higher there (Sainthamaruthu Divisional Secretariat [SDS], 2015).

Therefore, much work was done to determine the costs incurred to treat and manage the disease by diabetes patients in Sainthamaruthu, as this was the main research problem. So, the primary aim of this study was to evaluate the economic cost of diabetes on patients in Sainthamaruthu. In order to achieve this main objective, the study had to set three sub-objectives as well:

- To estimate the monthly average direct cost of care for patients with diabetes

- To assess the monthly average indirect cost of treating diabetic patients

- To put forward suitable suggestions to policy makers

\section{Research Area}

Sainthamaruthu is a developing town with strengths in the areas of education, business, agriculture, fisheries, sports, arts, culture and religion and this is the only city in Sri Lanka with a one hundred percent Muslim population. It is located on the east coast of Ampara District in the Eastern Province of Sri Lanka. It faces Sammanthurai to the West, Kalmunai DS division to the North, Karaitivu DS division to the South and the Bay 
of Bengal to the East. Total area of Sainthamaruthu is $9 \mathrm{~km}^{2}$ (3 Sq. mi). There were 25,412 people living in Sainthamaruthu in 2015 (SDS, 2015).

Sainthamaruthu is highly urbanized and congested due to several reasons, such as increasing commercial activities in the main area of the town, fishing operations on the eastern shore, while the areas in the west are fully engaged in paddy cultivation (www.sainthamaruthu.ds.gov.lk).

\section{Method and Techniques}

\subsection{Data Collection}

In order to achieve the objectives outlined earlier, data from both primary and secondary sources were collected. Both qualitative and quantitative methods were used for this study, with reliance being placed mostly on primary quantitative data.

Primary data were collected through personal interviews and the questionnaire. The sample for the questionnaire was selected through the stratified sampling method from 243 patients. 100 questionnaires were distributed through the random sampling method. Of the 243 diabetic patients, 134 were females and 109 were males (Sainthamaruthu Hospital Statistics, 2016). According to the stratified sampling method 55 and 45 questionnaires were distributed among males and females, respectively. It is explained by the formula below.

$$
\begin{array}{lrl}
\text { For female } & \frac{134}{243} \times 100=55 \\
\text { For male } & \frac{109}{243} \times 100=45
\end{array}
$$

Secondary data were collected from the records of hospital attendance at the two main hospitals in Sainthamaruthu (Km/ Ashraff Memorial Hospital \& Sainthamaruthu District Hospital). For the data analysis this study used the cross-sectional descriptive method to estimate the direct cost and indirect cost of diabetes among the people of the study area. This cost was calculated through the cost of illness method. This study also used SPSS and Excel.

\subsection{Methodology}

\subsubsection{Cost of illness method}

This approach is based on the costs of individual units of service obtained by the patient. It uses the average cost of service estimates and applies these data to the total number of health care encounters related to the disease to arrive at an estimate of the healthcare costs of a disease (Thomas J Songer \& Lorraine Ettaro, 1998).

$$
\begin{gathered}
\text { direct cost }= \\
\text { average cost of hospital care by specific diagnosis } \times \\
\text { total use for hospital service by specific diagnosis }
\end{gathered}
$$

In addition to the cost of illness method, the indirect cost of diabetes was calculated based on how much they were willing to pay to overcome their risk of illness. This information is obtained via the questionnaire. And total economic cost is the sum of direct cost and indirect cost (Thomas et al., 1998).

This study also described the results based on the average monthly costs incurred by diabetic patients by gender, age and income level. This was calculated using the following formula.

$$
\text { monthly average cost }=\frac{\text { Total cost of paticular variable }}{\text { Total number of patient in the variable }}
$$

\section{Results and Discussion}

This study was conducted based on the gathered primary data for the purpose of fulfilling its objectives. The selected research area was Sainthamaruthu Divisional Secretariat. This survey found that 18 percent of the people having diabetes were in the age group between 35-45 years, 36 percent were from 46 to 55 years, 40 percent were from 56-65 years, and 6 percent were from 66 to 75 years, respectively. If we examine the prevalence of diabetes according to income levels, those families earning up to US $\$ 60$ per month included 75 percent, families earning between US $\$ 60$ and US $\$ 175$ included 17 percent, and those earning between US $\$ 175$ and US \$350 included 8 percent (Computed Data, 2016).

According to this study, average monthly direct cost of diabetes in Sainthamaruthu was US \$19 and indirect cost was US $\$ 68.94$. So every month a patient had to spend US $\$ 87.94$ for the management of diabetes. Table 2 presents details of how much costs were incurred by diabetic patients each month in the study Area (Computed 
Data, 2016).

According to Table 2, direct costs include doctor's consultation fees, transport cost, cost for urine test, cost for blood test and cost of medication. In the study area, diabetic patients spent more money for medication than other services. Further, this research found that in respect of indirect cost of diabetes, people lost more money when they suffered permanent disability than from short term morbidity.

Table 2. Details of average monthly economic costs for diabetic patients in Sainthamaruthu

\begin{tabular}{lll}
\hline Type of Cost & Amount in US \$ & Total \\
\hline Direct cost & & \\
\hline Doctor's consultation fee & 5.15 & \\
Transportation cost & 1.12 & \\
Cost of urine test & 0.47 & \\
Cost of blood test & 1.32 & \\
Medication cost & 10.93 & 68.94 \\
\hline Indirect cost & & \\
\hline Short term morbidity & 19.74 \\
Permanent disability & 49.20 & 87.94 \\
\hline Total cost & & \\
\hline
\end{tabular}

(Source: Questionnaire Survey - 2016)

This study also analyzed the types of cost by gender, age and income-wise. These were estimated using the formula for average monthly cost that is given under heading No: 3.2.1. Based on that formula, the highest monthly average direct cost and indirect cost were incurred by the age group between 46 to 55 years. The amounts were US \$21.97 and US \$121.87, respectively.

Furthermore, based on the cost of illness method, highest annual total economic cost was incurred by the age group between 46 to 55 years, mostly because they did not follow the recommended diet. It accounted for 51 percent of the annual economic cost of diabetes in the study area. Other age groups of 35-45 years, 56-65 years and 66-75 years accounted for 16 percent, 31 percent and 2 percent respectively of the annual economic cost of diabetes.

If we look at the results based on the income level of people, the highest monthly average direct cost was incurred by the income group that earned between US \$175 and US \$350 per month. The highest monthly average indirect cost and total economic cost was incurred by the income group that earned between US \$60 and US $\$ 175$. Females were prone to diabetes more than males. Monthly average economic cost to males was US $\$ 125.01$. Economic cost incurred by females was US $\$ 57.58$ monthly. These results are presented in detail in Table 3 (Computed Data, 2016). 
Table 3. Details of monthly average costs of diabetes in Sainthamaruthu Divisional Secretariat

\begin{tabular}{|c|c|c|c|c|c|c|c|c|c|c|}
\hline \multirow[b]{2}{*}{ Variables } & \multicolumn{10}{|c|}{ Types of diabetic cost in US \$ } \\
\hline & $\begin{array}{l}\text { doctor } \\
\text { consultation } \\
\text { cost }\end{array}$ & $\begin{array}{l}\text { transportation } \\
\text { cost }\end{array}$ & $\begin{array}{l}\text { cost for } \\
\text { urine test }\end{array}$ & $\begin{array}{l}\text { cost for } \\
\text { blood } \\
\text { test }\end{array}$ & $\begin{array}{l}\text { medication } \\
\text { cost }\end{array}$ & $\begin{array}{l}\text { direct } \\
\text { cost }\end{array}$ & $\begin{array}{l}\text { short term } \\
\text { morbidity }\end{array}$ & $\begin{array}{l}\text { permanent } \\
\text { disability }\end{array}$ & $\begin{array}{l}\text { indirect } \\
\text { cost }\end{array}$ & $\begin{array}{l}\text { economic } \\
\text { cost }\end{array}$ \\
\hline \multicolumn{11}{|c|}{ Age Group } \\
\hline $35-45$ yrs & 5.71 & 1.08 & 0.27 & 0.79 & 7.91 & 15.76 & 46.58 & 0 & 46.58 & 62.35 \\
\hline 46-55 yrs & 6.65 & 1.04 & 0.62 & 1.62 & 12.02 & 21.97 & 85.9 & 35.98 & 121.87 & 143.87 \\
\hline 56-65 yrs & 4.86 & 1.02 & 0.43 & 1.68 & 13.79 & 21.79 & 33.04 & 24.19 & 57.22 & 78.98 \\
\hline 66-75 yrs & 1.07 & 1.73 & 0.61 & 0.61 & 5.23 & 9.24 & 6.32 & 0.97 & 7.29 & 16.54 \\
\hline \multicolumn{11}{|c|}{ Income Level } \\
\hline $\begin{array}{c}\text { US \$1 } \\
\text {-US \$60 }\end{array}$ & 5.56 & 1.14 & 0.47 & 0.96 & 13.75 & 19.11 & 12.73 & 21.02 & 33.75 & 52.87 \\
\hline $\begin{array}{c}\text { US \$60 } \\
\text {-US \$175 }\end{array}$ & 5.21 & 1.13 & 0.55 & 2.4 & 9.44 & 18.74 & 112.33 & 21.98 & 134.31 & 153.05 \\
\hline $\begin{array}{c}\text { US \$175 } \\
\text {-US \$350 }\end{array}$ & 4.87 & 1.2 & 0.31 & 1.18 & 10.97 & 21.3 & 27.74 & 2.92 & 30.66 & 51.96 \\
\hline & & & & & Gender & & & & & \\
\hline Male & 4.91 & 1.34 & 0.58 & 1.85 & 13.1 & 21.59 & 22.32 & 81.1 & 103.42 & 125.01 \\
\hline Female & 5.35 & 0.95 & 0.39 & 1.05 & 9.14 & 16.82 & 17.62 & 23.09 & 40.71 & $\mathbf{5 7 . 5 8 1}$ \\
\hline
\end{tabular}

(Source: Questionnaire Survey - 2016)

On the whole, people in the middle income groups (between US \$60 and US \$175) had to bear more annual economic costs than others, accounting for 45 percent of the total. The lower income level people (between US $\$ 1$ and US \$60) had to bear 29 percent of the total. Only 26 percent of the annual economic cost had to be borne by the higher income people (between US $\$ 175$ and US $\$ 350$ ).

The reason for this lopsided pattern is that lower income people are lacking in knowledge about diabetes and methods for controlling it. Even though prevalence of diabetes is decreasing among higher income people, they use advanced methods and techniques to manage it. There are also differences due to gender among diabetics. Many males indulge in overconsumption of fast food and sugar and also tend to eat out in hotels, food outlets and canteens at their workplace. They are also subject to more stress and lack time to exercise. Therefore, males have to spend more for the treatment than females.

Alberto Barcelo et al. (2003), Loganathan and John (2013) and Mudassar Hussain et al. (2004) found through their studies that diabetes imposed a very high economic burden on the individual and society in such places as Latin America, and the islands of the Caribbean. They also found that middle aged people in India and Pakistan had to bear higher costs to keep their diabetes in check. These findings are not very different from the findings of this research. Loganathan and John (2013) found that income and gender did not play a significant role in affecting the cost of diabetes treatment . Mudassar Hussain et al. (2004) and Katulanda, Sheriff and Matthews (2006) observed that females bore a higher cost of diabetes in Pakistan and Sri Lanka. But this contradicts the finding that low income people and males shared a higher cost in the selected study Area. According to Pablo Chandra et al. (2014), Ping Sang et al. (2010), Dawsan, Danial Goams and Hertizal (2002), and Hind Elrayah (2007), researchers found that the economic cost of diabetes in Pune was 10.4 percent. Global healthcare expenditure in 2010 was $\$ 418$ billion and it was likely between $\$ 4.76$ and $\$ 5.23$ billion in Canada in 1998 , to 
mention a few examples. This research found that the average monthly economic cost in the study area was US $\$ 87.93$.

\subsection{Suggestions for Policy Makers}

According to the findings of this study, patients go to the clinic in government hospital once a month. It should be changed to twice a month. In the study area lower income people are those affected most by the prevalence of diabetes. They are not well educated and so lack knowledge about diabetes and the methods for controlling it. Further, prevalence of diabetes is increasing gradually among the lower income people. So government hospitals should conduct awareness programs once a month. Like the food stamp programs, government could implement a diet food supply program for diabetic patients.

Due to the poor conditions in this study area, people face difficulty in the management of diabetes. So the government should increase the amount of Samurdhi and allocate an additional amount to manage the diabetes for the affected people. In the study area's government hospital, they do not even have a nutritionist. So policymakers should rectify that omission. In this place the hotels and canteens serve tea and coffee with sugar. Therefore, the government should bring in a rule that hotels and canteens serve the sugar separately with tea or coffee. If anyone breaks the rules, government should impose a fine on them.

\section{Conclusion}

The incidence of diabetes mellitus is increasing rapidly in the world. The economic burden of diabetes is a big problem for diabetic patients and their families. This research is a survey about the economic cost of diabetes in Sainthamaruthu in Ampara district in Sri Lanka.

The objective of this research was to ascertain the economic cost of diabetes in Sainthamaruthu divisional secretariat area. Based on this research the direct cost and indirect cost of diabetes was evaluated. Monthly average direct cost in the study area was US $\$ 19$ per diabetic. The monthly average doctor consultation cost was US $\$ 5.15$, monthly average transportation cost was US $\$ 1.12$, monthly average cost for urine test was US $\$ 0.47$, monthly average cost for blood test was US $\$ 1.32$ and monthly average medication cost was US \$10.93.

In addition, the monthly average indirect cost was US $\$ 68.94$. US $\$ 49.20$ is lost per patient by way of monthly permanent disability and US $\$ 19.74$ lost per patient as monthly short term morbidity. Therefore, monthly average economic cost in the study area is US $\$ 87.93$. Further, 54 percent of the patients are dependent on their families to help them meet the cost of diabetes. So a major part of the cost of diabetes treatment is imposed on the families of diabetic patients in the study area. And that is a big economic burden on them.

\section{Acknowledgements}

We thank the people who participated in the survey and interviews and supported us in various ways to conduct this research. We also thank the Senior Lecturers in the Department of Economics and Statistics, South Eastern University of Sri Lanka for their advice, suggestions and encouragement. We are deeply indebted to our families for their direct and indirect support during the entire course of this project. We are grateful to the Divisional Secretariat and all of the people in Sainthamaruthu who cooperated with us in many ways and helped us to complete this research project successfully.

\section{References}

Adam, W. (1986). The demand for health: theory and application. Journal of epidemiology and community health, 40, 1-11. https://doi.org/10.1136/jech.40.1.1

Ahuja, H. L. (2011). Advance economic theory. New Delhi, S.Chand and Company Ltd.

Alberto, B., Cristian, A., Swapnil, R., \& Sylvia, R. (2003). The cost of diabetes in Latin America and the Caribbean. Bulleding of the World Health Organization, 81(1), 19-27.

American Diabetes Association. (2013). Economic cost of diabetes in the U.S in 2012. America: diabetes care publish a head of print.

Boutayeb, W., Lamlili, M., Boutayeb, A., \& Boutayeb, S. (2013). Estimation of direct and indirect cost of diabetes in morocco. Research unit associated to CNRST, 6, 7432-738. https://doi.org/10.4236/jbise.2013.67090

Brackenridge, B. P., \& Richard. (1998). Diabetes 101: a pure and simple guide for people who use insulin. New York, John Willey \& sons.

Chandra, P., Gogate, B., Gogate, P., Thite, N., \& Walimbe, A. (2014). Economic burden of diabetes in urban Indians. The open ophthalmology, 8, 91-94. 
Charles, A. K., Mari, G., Erica, V, N., \& Alessandra, F. (2014). The economic burden in India: a review of literature.

Cobden, D. S. (2011). Economic implication of patient related factors in diabetes care. New York, Erasmus Universitat Rotterdam.

Grand Mosque: Sainthamaruthu- Maligaikadu. (2009). History of Sainthamaruthu. community welfare \& disaster management council Sainthamaruthu.

Hind Elrayah-Eliadarous. (2007). Economic burden of diabeties on patients and trhier families in Sudan', Karolinska instituted.

Husain, M., Shyum, S. B., Alam, S., \& Akram, M. (2014). Direct cost of treatment of diabetes mellitus type 2 in Pakistan. International journal of pharmacy and pharmaceutical science, 6(11), 261- 264.

Kanavos, P., Aardweg, S. V. D., \& Schurer, W. (2012) Diabetes expenditure, burden of disease and management in 5 EU countries. London: LSC health London school of economics.

Katulanda, P., Sheriff, M. R., \& Mathews, D. R. (2010). Province and ethnic specific prevalence of diabetes among Sri Lankan adults. Sri Lanka journal of diabetes endocrinology and metabolism, 2(7),

Katulanda, P., Sheriff, M. R., \& Mathews, D. R. (2010). The diabetes epidemic in Sri Lanka - a growing problem. Ceylon medical journal, 51(1), 26-28. https://doi.org/10.4038/cmj.v51i1.1373

Keith, G., Daniel, G., Hertzel, G., James, F., \& Kristijan, H. (2002). The economic cost diabetes in Canada 1998. Epidemiology health service psycho social research, 25, 1307-2002.

Khowaja, L., Khowaja, A., \& Cosgrove, P. (2007). Cost of diabetes care in out patient clinics of Karachi Pakistan. BMC health services, 189, 1-8. https://doi.org/10.1186/1472-6963-7-189

Loganathan, A. C. V., \& John, K. R. (2013). Economic burden of diabetes in people living with the diseases. Jurnal of diabetology, 3(4), 1-8.

Ramachantran, A. (2007). Socio- economic burden of diabetes in India. India diabetes research foundation. Japi, $55,9-12$.

Silva, P. D. (2016). Social cultural and economic determinants of diabetes mellitus in Kalutura Distric, Sri Lanka: a cross sectional descriptive study. International Journal for Equity in Health, 11(76), 2-6.

Songer, T. J., \& Ettaro, L. (1998). Studies on the cost of diabetes. Atlanta, economics of diabetes project panel.

Suhrcke, M., Rachel, A., Struckier, D., \& Rocco, L. (2006). Chronic Diseases: An economic perspective. London: Oxford health alliance.

World Health Organization. (2014). Who guide to identifiying the economic of disease and injury. Switzerland, department of health systems financing health system and services World Health Organization.

Zhang, P., Zhang, X. Z., Brown, J., Vistisen, D., \& Nichols, G. (2010). Global health care expenditure on diabetes for 2010 and 2030. Australia: Diabetes and clinical practice.

\section{Copyrights}

Copyright for this article is retained by the author(s), with first publication rights granted to the journal.

This is an open-access article distributed under the terms and conditions of the Creative Commons Attribution license (http://creativecommons.org/licenses/by/4.0/). 